Received: 2018.01.23

Accepted: 2018.02.02

Published: 2018.07 .02
Corresponding Author: Source of support:

\title{
Effects of 3-Tetrazolyl Methyl-3-Hydroxy- Oxindole Hybrid (THOH) on Cell Proliferation, Apoptosis, and G2/M Cell Cycle Arrest Occurs by Targeting Platelet-Derived Growth Factor D (PDGF-D) and the MEK/ERK Signaling Pathway in Human Lung Cell Lines SK-LU-1, A549, and A-427
}

Authors' Contribution: Study Design A Data Collection B Statistical Analysis C Data Interpretation D Manuscript Preparation E Literature Search F Funds Collection G
ABCEG 1 Peng Li

BDEF 2 Zhiqiang Zhang

BEF 3 Feng Zhang

BDF 4 Hongling Zhou

ADE 5 Bei Sun

\begin{abstract}
Department of Internal Medicine, Affiliated Cancer Hospital of Zhengzhou University, Henan Cancer Hospital, Zhengzhou, Henan, P.R. China 2 Department of Oncology, The Peoples' Hospital of Liaoning Province, Shenyang, Liaoning, P.R. China

3 Department of Thoracic Surgery, Huaihe Hospital of Henan University, Kaifeng, Henan, P.R. China.

4 Department of Oncology Medicine, Puyang Oilfield General Hospital, Puyang, Henan, P.R. China

5 Department of Respiration Medicine, The People's Hospital of Henan Province, Zhengzhou, Henan, P.R. China.
\end{abstract}

Background: The aim of this study was to evaluate the effects of 3-tetrazolyl methyl-3-hydroxy-oxindole hybrid (THOH) on cell proliferation, apoptosis, and the cell cycle in human lung cancer cell lines SK-LU-1, A549, and A-427, and the normal lung fibroblast cell line, MRC-5, in vitro.

Material/Methods: Human lung adenocarcinoma cells SK-LU-1, A549, and A-427, and the normal lung fibroblast cells, MRC-5 were cultured and treated with increasing concentrations of $10 \mathrm{mM}$ of a stock solution of $\mathrm{THOH}$ in dimethyl sulfoxide (DMSO). An MTT cell proliferation assay was used. Cell apoptosis and the cell cycle were studied using fluorescence-activated cell sorting (FACS) with fluorescein isothiocyanate (FITC), Annexin-V, propidium iodide (PI), and nuclear staining with 4',6-diamidino-2-phenylindole (DAPI). DNA damage was measured using the comet (single-cell gel electrophoresis) assay. Cell migration was evaluated using a wound healing assay, and Western blotting was used to measure protein expression levels.

Results: Treatment of SK-LU-1 cells with THOH inhibited cell migration. Treatment of lung cancer cells, SK-LU-1, A549, and A-427, with $\mathrm{THOH}$ inhibited cell proliferation, with the most marked inhibition found in the SK-LU-1 lung cancer cells $\left(\mathrm{IC}_{50}, 12 \mu \mathrm{M}\right)$. Treatment of lung cancer cells, SK-LU-1, A549, and A-427, with THOH increased cell apoptosis, resulted in G2/M cell cycle arrest, and inhibited both the platelet-derived growth factor D (PDGF-D) and MEK/ERK signaling pathways.

Conclusions: Treatment of adenocarcinoma cells, SK-LU-1, A549, and A-427, with THOH inhibited cell proliferation, apoptosis, and resulted in G2/M cell cycle arrest by targeting PDGF-D and the MEK/ERK signaling pathway.

MeSH Keywords: $\quad$ Apoptosis • Carcinoma, Non-Small-Cell Lung • Cell Cycle Checkpoints • Cell Migration Inhibition

Full-text PDF: https://www.medscimonit.com/abstract/index/idArt/909125

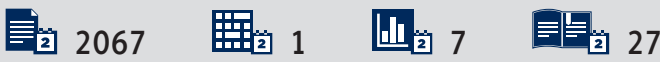




\section{Background}

Lung cancer is one of the most commonly diagnosed cancers in developed countries and has high rates of morbidity and mortality due to the difficulty in detecting early-stage cancer $[1,2]$. Because there may be few clinical symptoms associated with early-stage lung cancer, patients commonly (approximately $80 \%)$ present with late-stage lung cancer [3]. Although there is continuing research being undertaken to understand the mechanisms involved in the prevention, etiology, and treatment of lung cancer, including studies on targeted therapy based on molecular research, the prognosis for patients who present with lung cancer remains poor [4-8].

The approach for the treatment of lung cancer includes surgical tumor resection, chemotherapy, and radiation therapy, but in most cases, recurrence of lung cancer occurs following treatment, and in advanced-stage cases, only palliative treatment is given [9-15]. Therefore, there is a need for continuing research to discover novel molecules, which might prevent the recurrence of lung cancer, or inhibit tumor progression. During the past few decades, several anti-cancer agents have been investigated in clinical trials, but the development of drug resistance and the development of drug toxicity to some currently used anti-cancer drugs drive the need for the discovery of new chemotherapeutic agents in lung cancer [16-18].

Currently, synthetic chemists are combining potent anti-cancer molecules with the aim of developing improved chemotherapeutic hybrid agents, such as 3-Substituted-3-hydroxy-2oxindole as a synthetic scaffold for emerging anti-cancer drug development as well as its modified derivatives [19,20]. Some of the 3-Substituted-3-hydroxy-2-oxindoles have been shown to inhibit the proliferation of A549 lung adenocarcinoma cells in vitro [19]. Tetrazole-bearing compounds have also shown a broad spectrum of biological activities [21]. Therefore, it is possible that hybrid molecules formed from 3-Substituted-3hydroxy-2-oxindoles and tetrazole-bearing compounds might have potential anti-cancer therapeutic properties.

The aim of this study was to evaluate the effects of 3-tetrazolyl methyl-3-hydroxy-oxindole hybrid ( $\mathrm{THOH})$ on cell proliferation, apoptosis, and the cell cycle in human lung cancer cell lines SK-LU-1, A549, and A-427, and the normal lung fibroblast cell line, MRC-5, in vitro.

\section{Material and Methods}

\section{Cell lines and culture conditions}

The human lung cancer cell lines SK-LU-1, A549, A-427, and the normal lung fibroblast cell line, MRC-5, were obtained from the
Shanghai Xiang Shi Biotechnology Co., Ltd. (Shanghai, China). Cell culture was performed in Dulbecco's modified Eagle's medium (DMEM) containing 10\% fetal bovine serum (FBS) and antibiotics (100 U/ml penicillin and $100 \mu \mathrm{g} / \mathrm{ml}$ streptomycin). The cells were incubated in an incubator containing 95\% air and $5 \% \mathrm{CO}_{2}$ at room temperature, $37^{\circ} \mathrm{C}$. A $10 \mathrm{mM}$ stock solution of 3-tetrazolyl methyl-3-hydroxy-oxindole hybrid ( $\mathrm{THOH})$ was prepared in dimethyl sulfoxide (DMSO) medium and dilutions were performed in medium to the required concentration. The reagents for the (3-(4,5-dimethylthiazol-2-yl)-2,5-diphenyltetrazolium bromide) tetrazolium reduction colorimetric assay (MTT assay) and the DMSO were purchased from SigmaAldrich (St. Louis, MO, USA).

\section{The MTT colorimetric assay to assess cell metabolic activity}

The human lung cancer cells, SK-LU-1, A549, A-427, and the normal lung fibroblasts, MRC-5, were cultured in the 96-well plates containing DMEM medium at a density of $2 \times 10^{6}$ cells per well. The cells were then incubated for 48 hours with the conditioned medium containing $\mathrm{THOH}$ at $37^{\circ} \mathrm{C}$. After incubation, the cells were treated with a $5 \mathrm{mg}$ per $\mathrm{ml}$ solution of MTT for 4 hours. Extraction of the cells with acidic isopropyl alcohol was followed by absorbance measurement at $570 \mathrm{~nm}$ wavelength (A570) using an enzyme-labeling instrument, the BioTek ELx800 Absorbance Microplate Reader (BioTek Instruments, Inc., Winooski, VT, USA).

\section{Apoptosis assay using fluorescence microscopy}

The lung cancer SK-LU-1 cells were seeded into 6-well plates $\left(2 \times 10^{5}\right.$ cells per well) and treated with $\mathrm{THOH}$ at concentrations of $0,6,12$, and $24 \mu \mathrm{M}$ for 24 hours at $37 \mathrm{C}$. The cells were then stained with the nuclear stain, 4',6-diamidino-2-phenylindole (DAPI) for $20-30 \mathrm{~min}$ at $25^{\circ} \mathrm{C}$ to detect the apoptosis by fluorescence microscopy, as previously described [22]. The percentage of apoptotic cells were detected using a fluorescein isothiocyanate (FITC), Annexin-V, propidium iodide (PI) apoptosis detection kit according to the manufacturer's instructions. DNA damage was measured using the comet assay (singlecell gel electrophoresis assay), as previously described [23].

\section{Cell cycle analysis using fluorescence-activated cell sorting (FACs)}

To estimate the number of cells in each phase of the cell cycle, the THOH-treated SK-LU-1 lung cancer cells were harvested and washed with PBS. The cells were fixed with $70 \%$ ethanol for about an hour and then washed again with PBS. The cells were finally resuspended in a solution of $\mathrm{PI}(50 \mu \mathrm{l} / \mathrm{ml})$ and RNase 1 $(250 \mu \mathrm{g} / \mathrm{ml})$, followed by incubation for $30 \mathrm{~min}$ at room temperature. The analysis was performed using FACS cater-plus flow cytometry, with at least 10,000 cells counted per group. 


\section{Cell migration assay}

The cell migration potential of THOH-treated SK-LU-1 lung cancer cells was investigated using a wound healing assay. Briefly, $5 \times 10^{4}$ cells/well were seeded in 96 -well plates. The plates were incubated overnight at $37^{\circ} \mathrm{C}$ to allow the cells to adhere to the plates. A wound in the confluent cells was created by making a scratch using a sterile pipette tip after the cells reached confluence. The cells were then washed with PBS to clear the detached cells. The cells were monitored after a 20-hour interval and photographed.

\section{Western blot analysis}

The lung cancer cells treated with $\mathrm{THOH}$ or DMSO were collected and washed with a lysis buffer consisting of Tris- $\mathrm{HCl}$, sodium-dodecyl sulfate (SDS), mercaptoethanol, and glycerol.The extracts were boiled for $10 \mathrm{~min}$ in the presence of loading buffer followed by separation of cell extracts using $15 \%$ sodium dodecyl sulfate-polyacrylamide gel electrophoresis (SDS-PAGE) gel. The samples were then placed onto polyvinylidene fluoride (PVDF) membranes, blocked using $5 \%$ dried skimmed milk powder.

PVDF membranes were incubated overnight at $4^{\circ} \mathrm{C}$ with primary antibodies to MEK (Cat. No. sc-6250), and ERK (Cat. No. sc-92) obtained from Santa Cruz Biotechnology. The membranes were then incubated with horseradish peroxidase (HRP)-conjugated secondary biotinylated antibodies (Cat. No. sc-2372) at 1: 1,000 dilution, for 2 hours. The membranes were washed with PBS, followed by visualization of the immunoreactive bands using enhanced chemiluminescence $(E C L)$ with the ECL-PLUS Kit, according to the manufacturer's instructions (Pierce Biotechnology, Inc., Waltham, MA, USA). The bands were analyzed using the Gel Doc 2000 imaging system (Bio-Rad Laboratories $\mathrm{GmbH}$, Munich, Germany).

\section{Statistical analysis}

All experiments were performed in triplicate, and the results were expressed as the mean \pm standard deviation (SD). Oneway analysis of variance (ANOVA), followed by Tukey's t-test using GraphPad7 software was used for statistical analysis. A P-value of $P<0.01$ was considered as statistically significant.

\section{Results}

\section{Treatment with 3-tetrazolylmethyl-3-hydroxy-oxindole hybrid (THOH) reduced cell proliferation in human lung cancer cells, SK-LU-1, A549, and A-427 in vitro}

The antiproliferative effects of 3-tetrazolyl methyl-3-hydroxyoxindole hybrid $(\mathrm{THOH})$ were evaluated for three lung cancer
Table 1. $\mathrm{IC}_{50}$ values of $\mathrm{THOH}$ against different lung cancer and normal cell line determined by MTT assay.

\begin{tabular}{|cc|}
\hline Cell line & IC50 $(\boldsymbol{\mu M})$ \\
\hline SK-LU-1 & 12 \\
\hline A549 & 25 \\
\hline A-427 & 25 \\
\hline MRC-5 & 65 \\
\hline
\end{tabular}

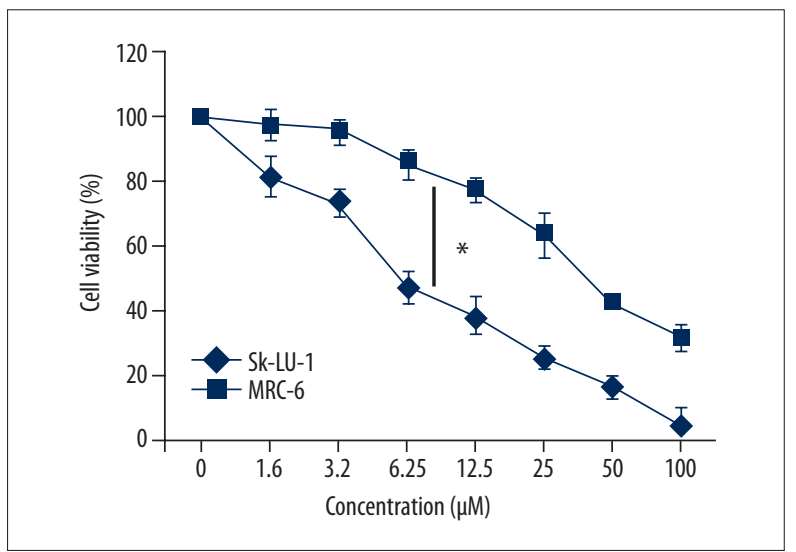

Figure 1. The MTT assay and the effects of 3-tetrazolyl methyl3-hydroxy-oxindole hybrid ( $\mathrm{THOH}$ ) on the cell viability of lung cancer cells, SK-LU-1, and the normal MRC5 cells. The experiments were carried out in triplicate, and the results are expressed as the mean \pm standard deviation (SD) $\left({ }^{*} \mathrm{P}<0.01\right)$.

cell lines, SK-LU-1, A549, and A-427, and the normal lung fibroblast cell line, MRC-5, in vitro. Treatment with $\mathrm{THOH}$ inhibited the proliferation of all the lung cancer cell lines (Table 1), but there was little effect on the normal MRC-5 cells. The greatest anti-proliferative effect was observed for the $\mathrm{THOH}$ treated SK-LU-1 cells, with an $\mathrm{IC}_{50}$ of $12 \mu \mathrm{M}$, the $\mathrm{IC}_{50}$ being the concentration of an inhibitor that results in a $50 \%$ reduced response (Figure 1). Therefore, the SK-LU-1 lung cancer cell line was carried forward for further studies.

\section{THOH treatment and apoptosis in lung cancer cells in vitro}

The treatment with $\mathrm{THOH}$ induced cell apoptosis in SK-LU-1 cells in a concentration-dependent manner (Figure 2). The percentage of apoptotic cells detected using a fluorescein isothiocyanate (FITC), Annexin-V, propidium iodide (PI) staining showed that the percentage of the apoptotic cells increased from $5.6 \%$ for the MRC- 5 control cells to $61.3 \%$ for the SK-LU- 1 cells treated with $\mathrm{THOH}$ at a concentration of $24 \mu \mathrm{M}$ (Figure 3). DNA damage, measured using the comet (single-cell gel electrophoresis) assay, also showed that $\mathrm{THOH}$ was associated with apoptosis via induction of DNA damage (Figure 4) 


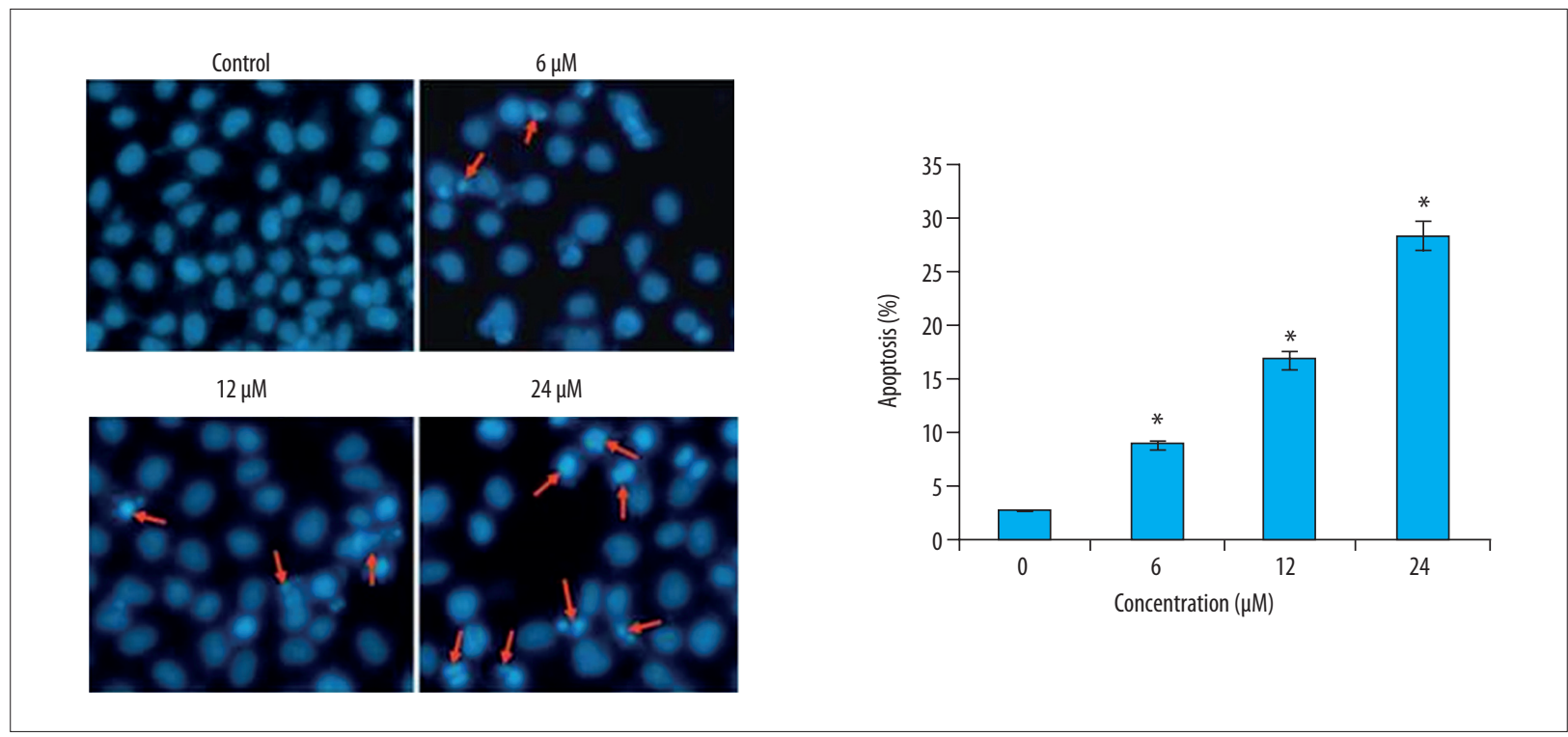

Figure 2. Cell apoptosis in SK-LU-1 cancer cells following treatment with 3-tetrazolyl methyl-3-hydroxy-oxindole hybrid (THOH) using fluorescence flow cytometry with Annexin V, propidium iodide (PI), and nuclear staining with 4',6-diamidino-2-phenylindole (DAPI). The experiments were carried out in triplicate, and the results are expressed as the mean \pm standard deviation (SD) $\left({ }^{*} \mathrm{P}<0.01\right)$.

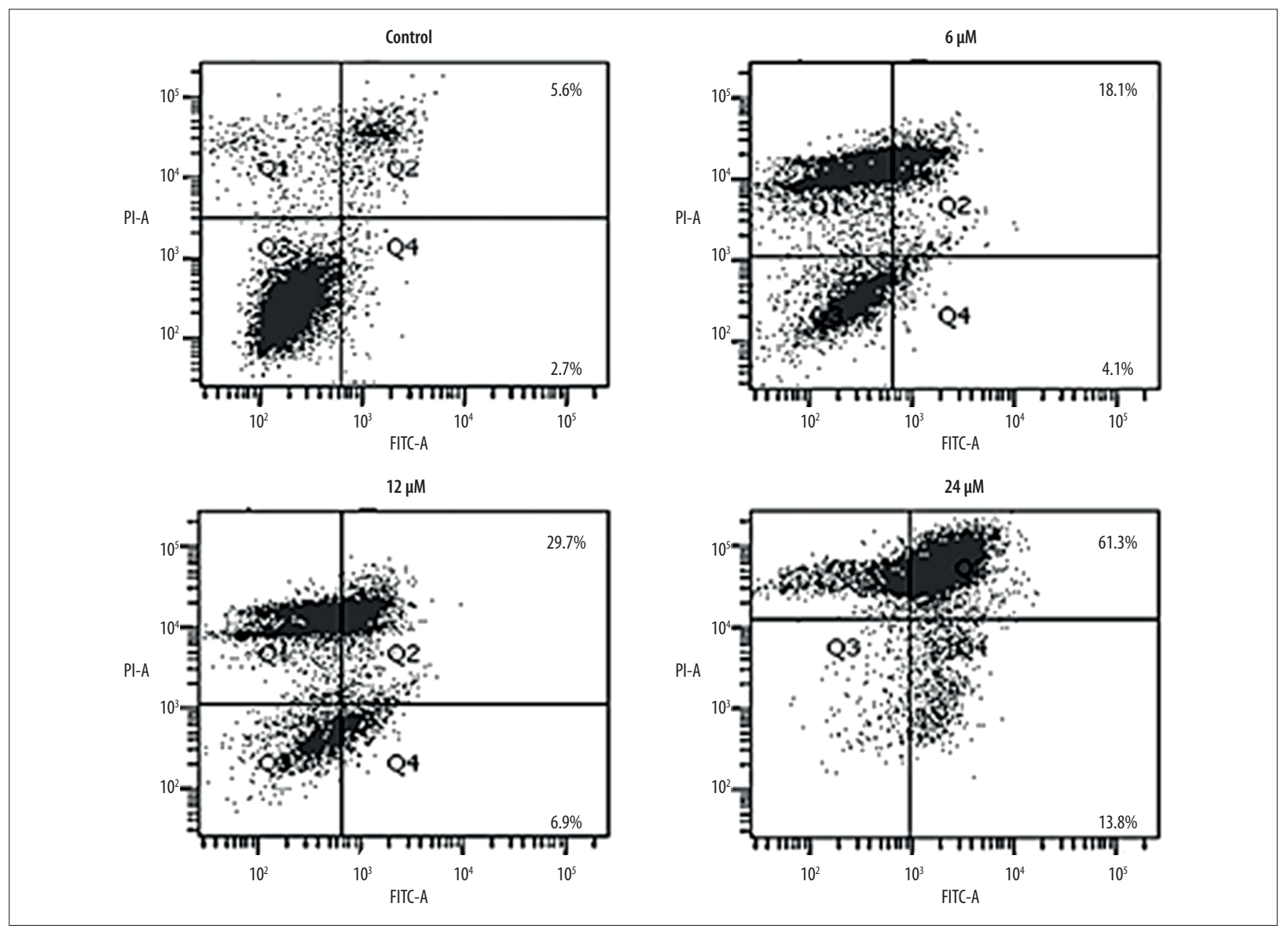

Figure 3. Cell apoptosis using fluorescence flow cytometry with Annexin V, propidium iodide (PI), and nuclear staining with 4',6-diamidino-2-phenylindole (DAPI). The experiments were carried out in triplicate. 

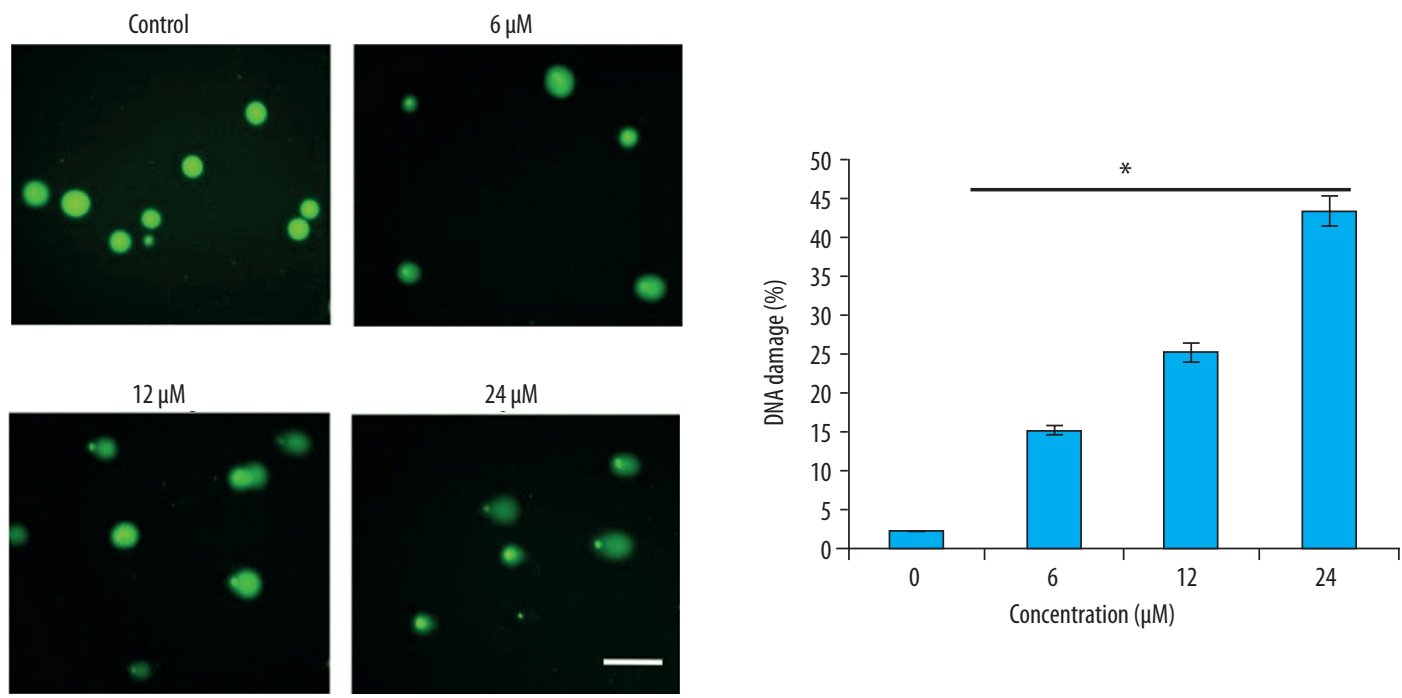

Figure 4. DNA damage, in the SK-LU-1 lung cancer cells, measured using the comet assay (single-cell gel electrophoresis assay), following treatment with 3-tetrazolyl methyl-3-hydroxy-oxindole hybrid ( $\mathrm{THOH})$. The experiments were carried out in triplicate.
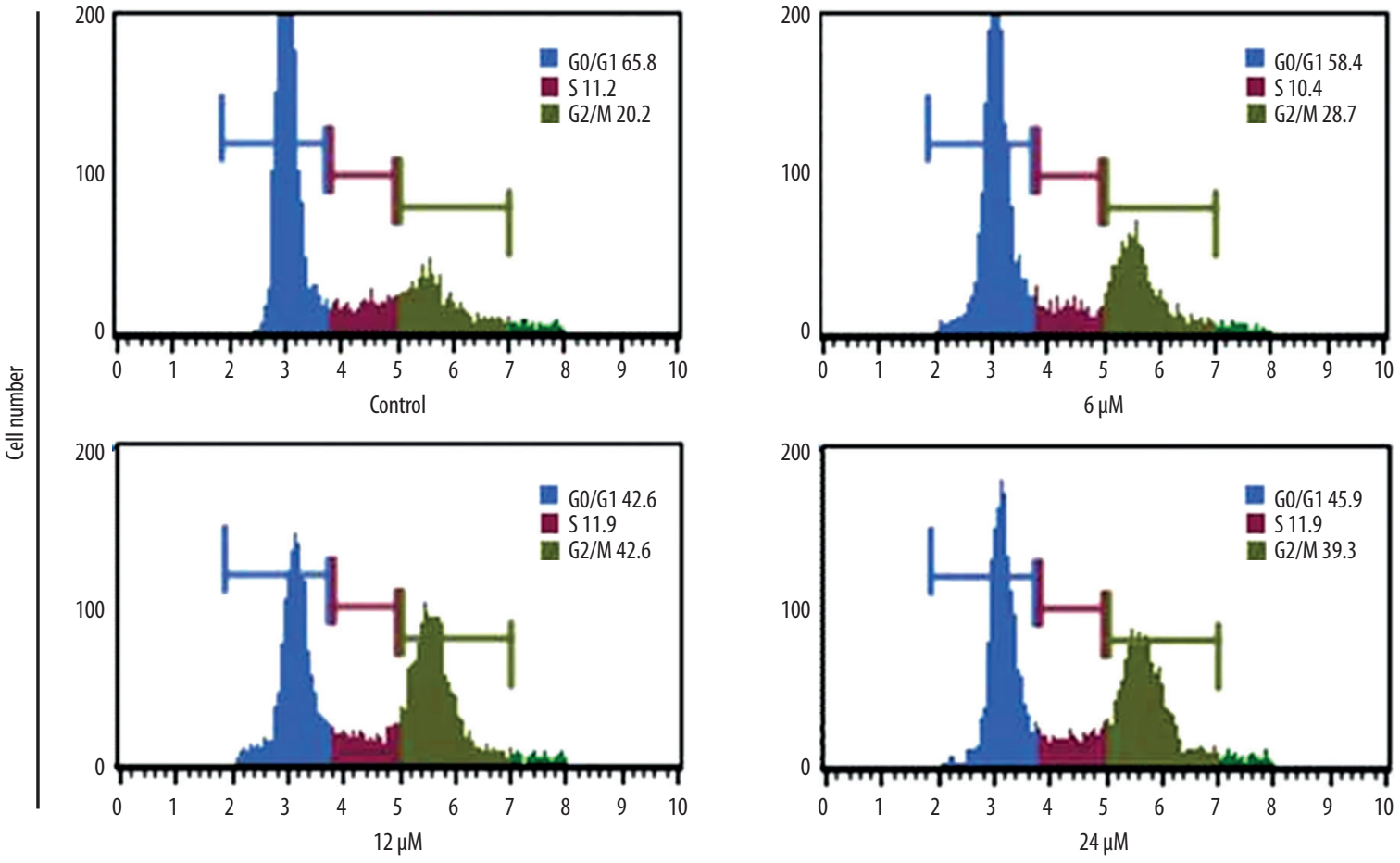

DNA content

Figure 5. Induction of G2/M cell cycle arrest of SK-LU-1 lung cancer cells, evaluated by flow cytometry, following treatment with 3-tetrazolyl methyl-3-hydroxy-oxindole hybrid ( $\mathrm{THOH})$. The experiments were carried out in triplicate. 


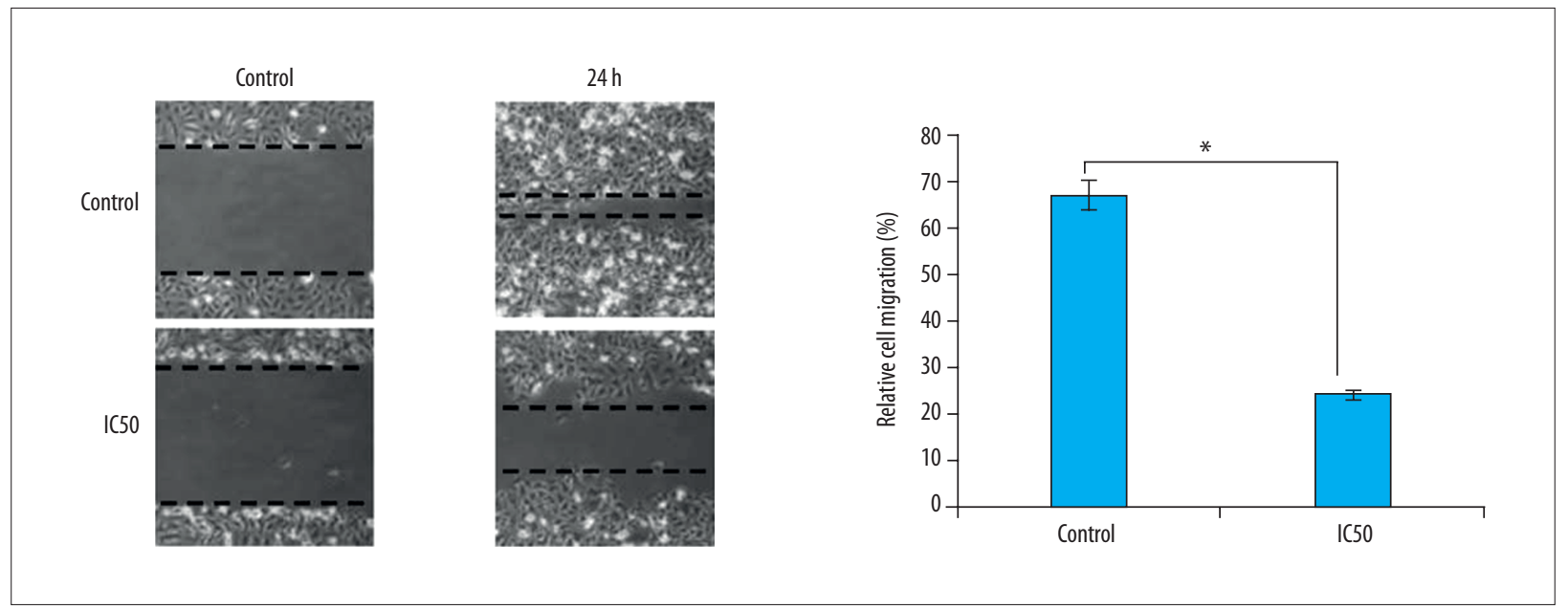

Figure 6. Inhibition of cell migration of SK-LU-1 lung cancer cells, evaluated using a wound healing assay, following treatment with 3-tetrazolyl methyl-3-hydroxy-oxindole hybrid $(\mathrm{THOH})$. The experiments were carried out in triplicate, and the results are expressed as the mean \pm standard deviation (SD) $\left({ }^{*} \mathrm{P}<0.01\right)$

A

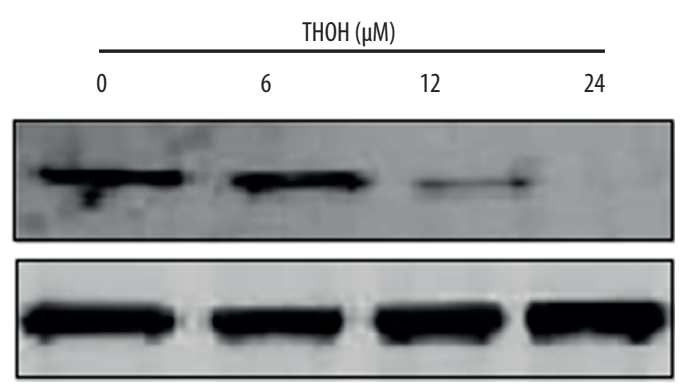

B

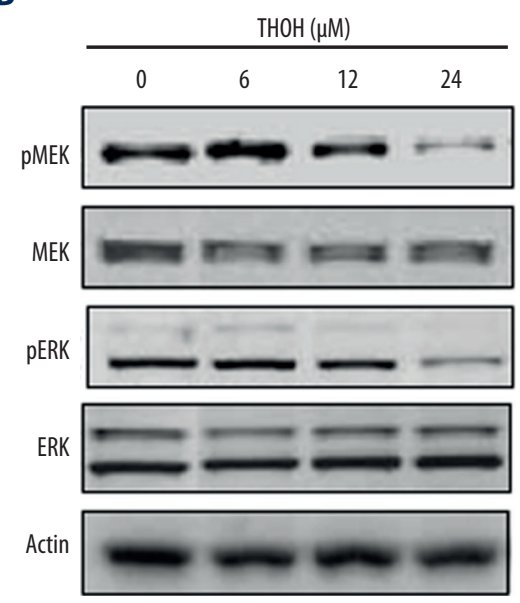

Figure 7. Western blot analysis of the proteins expressed following treatment of cells with 3-tetrazolyl methyl-3-hydroxy-oxindole hybrid (THOH). (A) Platelet-derived growth factor D (PDGF-D) signaling pathway proteins, detected by Western blot.

(B) MEK/ERK signaling pathway proteins, detected by Western blot. The experiments were carried out in triplicate.

\section{THOH treatment induced G2/M cell cycle arrest in lung cancer cells in vitro}

The effect of $\mathrm{THOH}$ treatment was also determined for the distribution of different phases of the cell cycle of the SK-LU-1 lung cancer cells in vitro. $\mathrm{THOH}$ treatment induced the accumulation of SK-LU-1 cells in the G2 phase of the cell cycle and triggered cell cycle arrest (Figure 5). The effect of $\mathrm{THOH}$ treatment on the cell cycle of the SK-LU-1 lung cancer cells was also found to be concentration-dependent.

\section{THOH treatment inhibited cell migration of lung cancer cells in vitro}

Because cell migration is an important aspect of cancer invasion and metastasis, the effect of $\mathrm{THOH}$ treatment on SKLU-1 cancer cell migration was investigated. THOH treatment was shown to inhibit the migration of the SK-LU-1 lung cancer cells at the $\mathrm{IC}_{50}$ dose of $12 \mu \mathrm{M}$ (Figure 6). 


\section{THOH treatment targeted the platelet-derived growth factor D (PDGF-D) and MEK/ERK signaling pathways}

Treatment of lung cancer cells with $\mathrm{THOH}$ inhibited the expression of platelet-derived growth factor D (PDGF-D) in a concentration-dependent manner (Figure 7A). Treatment of lung cancer cells with $\mathrm{THOH}$ inhibited the expression of $\mathrm{p}-\mathrm{MEK}$ and $\mathrm{p}$-ERK in a concentration-dependent manner, but the expression of MEK and ERK was unchanged (Figure 7B).

\section{Discussion}

Despite recent research on the molecular biology of lung cancer and drug development of targeted treatment, worldwide, lung cancer remains as one of the most prevalent types of cancer, and because it is often detected at an advanced stage, it remains difficult to treat $[1,2]$. Because of the need for continued studies on novel molecules for the treatment of lung cancer, in the present study, the anticancer effects of 3-tetrazolyl methyl-3-hydroxy-oxindole hybrid $(\mathrm{THOH})$ was evaluated against a panel of lung cancer cell lines, SK-LU-1, A549, and A-427, and the normal lung fibroblast cells, MRC-5.

The preliminary results of this study showed that treatment of lung cancer cell lines with $\mathrm{THOH}$ inhibited cell proliferation, which was less than that found in the normal lung cell line MRC-5. Also, out of all the cell lines, the anti-cancer effects of $\mathrm{THOH}$ were more pronounced in the SK-LU-1 lung cancer cells, and so this cell line was used for further studies on the effects of $\mathrm{THOH}$ treatment.

Because different anticancer agents exert their antiproliferative effects via different mechanisms [23], in this study, a preliminary investigation of the underlying mechanism for the anticancer activity of $\mathrm{THOH}$ was undertaken. The study findings showed that $\mathrm{THOH}$ treatment of lung cancer cells in vitro could trigger cell cycle arrest in SK-LU-1 lung cancer cells as shown by fluorescence-activated cell sorting (FACs) with fluorescein isothiocyanate (FITC), Annexin-V, propidium iodide (PI), and nuclear staining with 4',6-diamidino-2-phenylindole (DAPI) and shown by DNA damage as measured using the comet (single-cell gel electrophoresis) assay. Apoptosis is an important mechanism by which many of the currently used anticancer agents exert their effects [24]. Also, induction of apoptosis by anticancer agents prevents the development of drug resistance in cancer cells [25].

In addition to apoptosis, cell cycle arrest is a further mechanism of action for anti-cancer drugs that inhibit the proliferation of cancer cells [26]. The cell cycle is controlled at two main checkpoints, the G1/S transition, and the G2/M transition. The G2/M checkpoint has an important role in the preservation of chromosomal integrity by permitting cells to repair DNA damage before entering mitosis [26]. The findings of this study showed that $\mathrm{THOH}$ induced G2/M cell cycle arrest, and could also inhibit the migration of the lung cancer cells, which indicate that $\mathrm{THOH}$ might have the potential to be developed as an anti-cancer drug, depending on future studies.

The expression of RAS genes are associated with oncogenesis and might be target candidates for drug development in cancer chemotherapy, and molecules that directly target the RAF gene, RAF kinases, or mitogen-activated protein (MAP) kinase or MEK in the MAP kinase pathway downstream of RAS have shown promising results in clinical trials [27]. Therefore, as part of this study, the effect of $\mathrm{THOH}$ on the expression of platelet-derived growth factor D (PDGF-D) and MEK/ERK signaling pathways were studied, and the findings showed that $\mathrm{THOH}$ could inhibit both of these signal transduction pathways.

\section{Conclusions}

The findings of this preliminary in vitro study showed that treatment of lung adenocarcinoma cells, SK-LU-1, A549, and A-427, with the compound 3-tetrazolyl methyl-3-hydroxy-oxindole hybrid $(\mathrm{THOH})$, inhibited cell proliferation, apoptosis, and resulted in G2/M cell cycle arrest by targeting the platelet-derived growth factor D (PDGF-D) and MEK/ERK signaling pathways. Further studies are recommended to investigate the mechanism of action of $\mathrm{THOH}$ to determine the potential role of this compound, and similar compounds, in the treatment of human cancer, including non-small cell lung cancer (NSCLC).

\section{References:}

1. Scheff RJ, Schneider BJ: Non-small cell lung cancer: Treatment of late-stage disease: Chemotherapeutics and new frontiers. Semin Intervent Radiol, 2013; 30: 191-98

2. Humphrey LL, Deffebach M, Pappas $M$ et al: Screening for lung cancer with low-dose computed tomography: A systematic review to update the US Preventive Services Task Force recommendation. Ann Intern Med, 2013; 159: 411-20

3. Becker N, Motsch E, Gross ML et al: Randomized study on early detection of lung cancer with MSCT in Germany: Study design and results of the first screening round. J Cancer Res Clin Oncol, 2012; 138: 1475-86

4. Zhu X, Jiang H, Li J et al: Anticancer effects of paris saponins by apoptosis and PI3K/AKT pathway in gefitinib-resistant non-small cell lung cancer. Med Sci Monit, 2016; 22: 1435-41

5. Zhang J, Yang Y, Lei L, Tian M: Rhizoma paridis saponins induces cell cycle arrest and apoptosis in non-small cell lung carcinoma A549 Cells. Med Sci Monit, 2015; 21: 2535-41

6. Zhang K, Qin H, Pan F et al: Nedaplatin or oxaliplatin combined with paclitaxel and docetaxel as first-line treatment for patients with advanced nonsmall cell lung cancer. Med Sci Monit, 2014; 20: 2830-36 
7. Palka M, Sanchez A, Córdoba $M$ et al: Cisplatin plus vinorelbine as induction treatment in stage IIIA non-small cell lung cancer. Oncol Lett, 2017; 13: $1647-54$

8. Jemal A, Siegel R, Ward E et al: Cancer statistics, 2008. Cancer J Clin, 2008; 58: 71-96

9. Asamura H, Goya T, Koshiishi Y et al: A Japanese Lung Cancer Registry study: Prognosis of 13,010 resected lung cancers. J Thorac Oncol, 2008; 3: 46-52

10. Mountain CF: Revisions in the International System for Staging Lung Cancer. Chest, 1997; 111: 1710-17

11. Tsuboi M, Ohira T, Saji H et al: The present status of postoperative adjuvant chemotherapy for completely resected nonsmall cell lung cancer. Ann Thorac Cardiovasc Surg, 2007; 13: 73-77

12. Tremblay G: Stromal aspects of breast carcinoma. Exp Mol Pathol, 1979; 31: 248-60

13. Gabbiani G, Ryan GB, Majne G: Presence of modified fibroblasts in granulation tissue and their possible role in wound contraction. Experientia, 1971; 27: 549-50

14. Rønnov-Jessen L, Petersen OW, Koteliansky VE, Bissell MJ: The origin of the myofibroblasts in breast cancer. Recapitulation of tumor environment in culture unravels diversity and implicates converted fibroblasts and recruited smooth muscle cells. J Clin Invest, 1995; 95: 859-73

15. Olumi AF, Grossfeld GD, Hayward SW et al: Carcinoma-associated fibroblasts direct tumor progression of initiated human prostatic epithelium. Cancer Res, 1999; 59: 5002-11

16. Okusa Y, Ichikura T, Mochizuki H: Prognostic impact of stromal cell-derived urokinase-type plasminogen activator in gastric carcinoma. Cancer, 1999; 85: $1033-38$
17. Forsberg K, Valyi-Nagy I, Heldin $\mathrm{CH}$ et al: Platelet-derived growth factor (PDGF) in oncogenesis: development of a vascular connective tissue stroma in xenotransplanted human melanoma producing PDGF-BB. Proc Natl Acad Sci USA, 1993; 90: 393-97

18. Baselga J, Swain SM: Novel anticancer targets: revisiting ERBB2 and discovering ERBB3. Nat Rev Cancer, 2009; 9: 463-75

19. Peddibhotla S: 3-Substituted-3-hydroxy-2-oxindole, an emerging new scaffold for drug discovery with potential anti-cancer and other biological activities. Curr Bioact Compd, 2009; 5: 20-38

20. Galliford CV, Scheidt KA: Pyrrolidinyl-spirooxindole natural products as inspirations for the development of potential therapeutic agents. Angew Chem Int Ed, 2007; 46: 8748-58

21. Bavetsias V, Marriott JH, Melin C et al: Design and synthesis of Cyclopenta[g] quinazoline-based antifolates as inhibitors of thymidylate synthase and potential antitumor agents. J Med Chem, 2000; 43: 1910-26

22. Hamada S, Fujita S: DAPI staining improved for quantitative cytofluorometry. Histochem Cell Biol, 1983; 79: 219-26

23. Marks PA: Discovery and development of SAHA as an anticancer agent. Oncogene, 2007; 26: 1351-56

24. Yu J, Zhang L, Hwang PM et al: PUMA induces the rapid apoptosis of colorectal cancer cells. Mol Cell, 2001; 7: 673-82

25. Fisher DE: Apoptosis in cancer therapy: Crossing the threshold. Cell, 1994; 78: 539-42

26. Hartwell LH, Kastan MB: Cell cycle control and cancer. Science, 1994; 266(5192): 1821-28

27. Chatterjee S, Rhee Y, Chung PS et al: Sulforaphene enhances the efficacy of photodynamic therapy in anaplastic thyroid cancer through Ras/RAF/MEK/ ERK pathway suppression. J Photochem Photobiol B, 2018; 179: 46-53 